\title{
Antioxidant Properties and Glucan Compositions of Various Crude Extract from Lentinus squarrosulus Mycelial Culture
}

\author{
Rahayu Ahmad, Sutha Muniandy, Nur Iffah Abdullah Shukri, Siti Mariatul Usyida Alias, \\ Aidil Abdul Hamid, Wan Mohtar Wan Yusoff, Sahidan Senafi, Fauzi Daud \\ School of Bioscience and Biotechnology, Faculty Science and Technology, National University of Malaysia, \\ Bangi, Malaysia \\ Email: fauzid@ukm.my
}

Received 5 July 2014; revised 9 August 2014; accepted 4 September 2014

Copyright (C) 2014 by authors and Scientific Research Publishing Inc.

This work is licensed under the Creative Commons Attribution International License (CC BY). http://creativecommons.org/licenses/by/4.0/

\section{(c) (i) Open Access}

\section{Abstract}

Various crude extracts of Lentinus squarrosulus mushroom mycelium and culture broth were prepared for antioxidant studies, glucan and carbohydrate compound analysis. Crude extract from ethanol, cold and hot water extraction was tested on several complementary test systems namely DPPH free radical scavenging, $\beta$-carotene linoleic acid oxidation, total phenolic compound, total flavonoid compound, total carbohydrate content and total glucan compositions. The antioxidant activity of the crude extracts of Lentinus squarrosulus mushroom mycelium and culture broth was determined by 2,2' diphenyl-1-picrylhydrazyl (DPPH) radical scavenging method and $\beta$-carotene linoleic acid assay. Crude extracted from culture broth EPS EE recorded the highest radical scavenging effects at $20 \mathrm{mg} / \mathrm{mL}(\mathbf{8 5 \%})$ which is closer to the control antioxidants (ascorbic acid 97\%; BHT 92.4\%; BHA 93.6\%). Both the ethanol extract (IPS EE and EPS EE) exhibited the highest $\beta$-carotene linoleic acid oxidation by recording $\mathrm{IC}_{50}$ values of 0.6 and $0.65 \mathrm{mg} / \mathrm{mL}$ respectively. IPS EE $(0.59 \mathrm{mg} / \mathrm{g})$ and EPS WE $(0.58 \mathrm{mg} / \mathrm{g})$ showed high flavonoid content whereas total phenol content was high in EPS WE $(0.85 \mathrm{mg} / \mathrm{g})$ and IPS EE $(0.84 \mathrm{mg} / \mathrm{g})$. Total carbohydrate concentrations were high in IPS HWE and IPS CWE with 19.1 and $16.3 \mathrm{mg} / \mathrm{mL}$ respectively and these data correlate with the $\beta$-glucan content in both extracts. The highest $\beta$-glucan content found in IPS CWE and IPS HWE were 12.2 and $11.4 \%$ w/w respectively.

\section{Keywords}

Lentinus squarrosulus, $\beta$-Glucan, Antioxidant, Polysaccharides, Submerged Fermentation 


\section{Introduction}

Lentinus squarrosulus is an edible mushroom commonly found in the wild and has not been cultivated on large scale for the production of fruit bodies. The tough fruit body is rich in proteins, sugars, lipid, amino acids, vitamin B, C, and D, and minerals [1]. Liquid fermentation of Lentinus squarrosulus mushroom produces high amounts of uniform mycelia biomass in the culture broth which was found as source of polysaccharide [2]. Previous research reported that batch cultures using Pleurotus ferulae, Pleurotus nebrodensis, and Agrocybe aegerita effectively produced polysaccharides and mycelia growth from liquid cultures [3]-[7]. It is also reported that Auricularia auricular judae, Pleurotus squarrosulus and Russula sp. contain appreciable amounts of alkaloids, phenols, saponins and flavonoids [8].

In many living organisms, oxidation is essential for the production of energy to accelerate biological processes. However, when the mechanism of oxidation becomes unbalanced by factors such as aging, deterioration of physiological functions may occur resulting in diseases such as cancer, rheumatoid arthritis, and atherosclerosis [9]. Thus, maintenance of equilibrium between free radical production and antioxidant defenses (enzymatic and nonenzymatic) is an essential condition for normal organism functioning. Antioxidant supplements or foods containing antioxidants may be used to help the human body reduce oxidative damage [10]. Antioxidants are compounds that can delay or inhibit the mechanism of oxidation by blocking the initiation or propagation of oxidizing chain reactions. Several commercial synthetic antioxidants are widely used in food industry such as butylatedhyroxyanisole (BHA), butylatedhydroxytoluene (BHT), andtert-butylhydroquinone (TBHQ) [11]. However, the utilization of these synthetic antioxidants becomes restricted due to their toxicity and carcinogenicity effects to the liver. Therefore, it is necessary to investigate and produce more effective natural antioxidants that are less harmful to human body.

In searching for new therapeutics alternatives, many kinds of mushrooms particularly higher Basidiomycetes have been studied extensively and have found variable therapeutic activities such as anticarcinogenic, anti-inflammatory, immuno-suppresor, antibiotic [12] [13] and anticancer [14]. These therapeutic activities are contributed by the antioxidants that are present in the foods. The antioxidant is defined as a substance in food that when present at low concentrations, it could significantly decrease or prevent the adverse effects of reactive species, such as reactive oxygen and nitrogen species (ROS/RNS), on normal physiological function in humans [8].

In previous research, water extraction of Lentinus squarrosulus mycelium homogenized with mycelia broth was tested on the free radical scavenging activity of DPPH and results showed that the extract exhibited more than $50 \%$ of inhibition [15]. To the best of our knowledge, no research has been conducted on antioxidant activities of various crude extracts from mycelium and culture broth of Lentinus squarrosulus in literature. Therefore, this study will evaluate more details on the antioxidant capacity from various types of extractions and glucan content as a valuable compound for anticancer treatment. As far as it is concerned, this is the first data demonstrated the glucan composition particularly $\alpha$ and $\beta$ glucan from Lentinus squarrosulus cultured mycelium and cultured broth.

\section{Materials and Method}

\subsection{Mushroom Mycelia}

Mushroom mycelia of Lentinus squarrosulus were maintained on potato dextrose agar (PDA) slant (30 g/L) added with $2 \%$ yeast extract, stored at $4{ }^{\circ} \mathrm{C}$ for long term use. The mycelium from stock culture was placed in the center on PDA plate and incubated for 7 days prior to submerged liquid fermentation.

\subsection{Chemicals}

Linoleic acid, $\beta$-carotene, 2,2-diphenyl-1-picrylhydrazyl (DPPH), butylatedhydroxytoluene (BHT), buthylatedhydroxyanisol (BHA), Tween 40, Folin-Ciocalteau's phenol reagent (FCR), sodium carbonate, and aluminum nitrate were purchased from Sigma-Aldrich. All other unlabeled chemicals and reagents were analytical grade.

\subsection{Submerged Liquid Fermentation}

Submerged liquid fermentation was carried out for production of mycelium using optimized culture conditions (sucrose concentration $114.61 \mathrm{~g} / \mathrm{L}$, yeast extract $1.62 \mathrm{~g} / \mathrm{L}$ and initial $\mathrm{pH}$ of 5.81) as described by [2]. A $5 \mathrm{~mm}$ 
plug of Lentinus sq. mycelia was removed with a cork borer from 7 day-old-culture. The mycelia cut (10 plugs) was transferred into liquid medium, incubated in orbital shaker for 7 days at $28^{\circ} \mathrm{C}, 150 \mathrm{rpm}$ for mycelia growth. Cultured mycelia were then dried using oven until constant weight. Dried mycelia were used for intracellular polysaccharide (IPS) extraction using ethanol, cold water and hot water method. Culture filtrates were used for extracellular polysaccharide (EPS) extraction using ethanol and water extraction method. EPS water extract were prepared by directly subjecting the culture filtrate to freeze-dryer yielding the exopolysaccharide water extract (EPS WE).

\subsection{Extraction of Polysaccharide}

\subsubsection{Ethanol Extraction}

Ethanol extraction was conducted according to the method used by [16]. Culture filtrates were mixed with 4 times of absolute ethanol, stirred vigorously and kept overnight at $4^{\circ} \mathrm{C}$. Ethanol was removed using rotary evaporator and crude extracts were dried using freeze dryer yielding the extracellular polysaccharide ethanol extracts (EPS EE). For intracellular polysaccharide ethanol extracts (IPS EE), a modified hot water extraction as described by [17] was used. Briefly, the powders of dried mycelia ( $40 \mathrm{~g})$ were extracted twice with distilled water $(600 \mathrm{~mL})$ at $100^{\circ} \mathrm{C}$ for $3 \mathrm{~h}$ in a water bath. The extracts were cooled, filtered using filter paper (Whatman No 1) and precipitated using ethanol before dried using freeze dryer.

\subsubsection{Cold Water Extraction}

Approximately $5 \mathrm{~g}$ of mycelia powder were mixed with $500 \mathrm{~mL}$ of distilled water and stirred vigorously for $3 \mathrm{~h}$ at room temperature. The extracts were filtered using Whatman No. 1 and the culture filtrates were freeze dried for intracellular polysaccharides cold water extracts (IPS CWE).

\subsubsection{Hot Water Extraction}

Intracellular polysaccharide hot water extracts (IPS HWE) were extracted using the method as described by [17]. Briefly, $40 \mathrm{~g}$ of dried mycelia powder was extracted twice with distilled water $(600 \mathrm{~mL})$ at $100^{\circ} \mathrm{C}$ for $3 \mathrm{~h}$ in water bath. The extracts were cooled, filtered and the filtrates were dried using freeze dryer.

\subsection{Antioxidant Test}

\subsubsection{DPPH Assay}

This spectrophotometric assay uses the stable radical DPPH reagent [18] [19]. In this assay the ability of the hydrogen or electron donation of the extracts were measured from the bleaching of the purple color methanol solution of DPPH. Different concentrations of the crude extract $(1 \mathrm{~mL})$ in distilled water were added to $4 \mathrm{~mL}$ of $0.004 \%$ methanol solution of DPPH. The mixtures were incubated at room temperature, in the dark for $30 \mathrm{~min}$ before read the absorbance against a blank at $517 \mathrm{~nm}$. Inhibition of free radical by DPPH in percent (I\%) was calculated in following way:

$$
\text { Scavenging effect }(\%)=\left(\mathrm{A}_{\text {blank }}-\mathrm{A}_{\text {sample }} / \mathrm{A}_{\text {blank }}\right) \times 100
$$

where $A_{\text {blank }}$ is the absorbance of the control reaction (containing all reagents except the test compound), and $\mathrm{A}_{\text {sample }}$ is the absorbance of the test compound. The value of $50 \%$ inhibition $\left(\mathrm{IC}_{50}\right)$ was calculated from the graph plotted inhibition percentage against extract concentrations. Tests were carried out in triplicate.

\subsection{2. $\beta$-Carotene Linoleic Acid Assay}

$\beta$-carotene linoleic acidassay was conducted according to the method of [20] and [21]. A stock solution of $\beta$-carotene-linoleic acid mixture was prepared as follows: $0.5 \mathrm{mg} \beta$-carotene was dissolved in $1 \mathrm{~mL}$ of chloroform (HPLC grade) and $25 \mu \mathrm{L}$ linoleic acid and $200 \mathrm{mg}$ Tween 40 were added. Chloroform was completely removed using a vacuum evaporator and $100 \mathrm{~mL}$ of distilled water was added and vigorously shaking. Then, $4 \mathrm{~mL}$ of the reaction mixture was dispensed into test tubes and $200 \mu \mathrm{L}$ portions of the extracts (prepared at $2 \mathrm{mg} / \mathrm{mL}$ ) were added and the emulsion system was incubated for $2 \mathrm{~h} \mathrm{at} 50^{\circ} \mathrm{C}$. As soon as the emulsion was added to each tube, the zero time absorbance at $490 \mathrm{~nm}$ was measured. Lipid peroxidation inhibition was calculated using the following equation: ( $\beta$-carotene content after $2 \mathrm{~h}$ of assay)/(initial $\beta$-carotene content) $\times 100$. The same procedure was repeated with synthetic antioxidants, which are BHA and BHT as positive control. Antioxidative ca- 
pacities of the extracts were compared with those of BHA, BHT, and blank. Tests were carried out in triplicate.

\subsection{Determination of Antioxidant and Anticancer Aompound}

\subsubsection{Total Phenolic Compound}

Total soluble phenolic in the various crude extracts were determined with Folin-Ciocalteau's phenol reagent (FCR) according to the method of [22] and [23]. Briefly, $1 \mathrm{~mL}$ of extract solution (2 g/L) was added with $46 \mathrm{~mL}$ of distilled water and $1 \mathrm{~mL}$ of Folin-Ciocalteau's phenol reagent and the content of the flask were mixed thoroughly. After $3 \mathrm{~min}, 3 \mathrm{~mL}$ of $\mathrm{Na}_{2} \mathrm{CO}_{3}(2 \%)$ was added and the mixture was allowed to stand for reading absorbance at $760 \mathrm{~nm}$. Gallic acid $(0.05-0.8 \mathrm{mM})$ was used as a standard, and the results were expressed as $\mathrm{mg}$ of Gallic acid equivalents per gram of extract.

\subsubsection{Total Flavanoid Compound}

Total flavonoid compound in the various crude extracts were determined according to the method of [24]. Briefly, $1 \mathrm{~mL}$ sample from various extracts solution $(2 \mathrm{mg} / \mathrm{mL})$ were diluted with $4.3 \mathrm{~mL}$ of $80 \%$ aqueous ethanol. The mixtures were then added with $0.1 \mathrm{~mL}$ of $10 \%$ aluminium nitrate and $0.1 \mathrm{~mL}$ aqueous potassium acetate $(1 \mathrm{M})$. The mixtures were incubated at room temperature for $40 \mathrm{~min}$ before read the absorbance using spectrophotometer at $415 \mathrm{~nm}$. Total flavonoid compound was calculated using Quercetin as a standard and the data was depicted as mg of Quercetin equivalents per gram of extracts.

\subsubsection{Total Carbohydrate Concentration}

Carbohydrate concentrations of various crude extracts were detected according to the slightly modified method of phenol-sulfuric acid assay by [25]. The crude extracts were suspended in distilled water $(1 \mathrm{mg} / \mathrm{mL})$ and $1 \mathrm{~mL}$ of sample solution were slowly mixed with $2.5 \mathrm{~mL}$ of $\mathrm{H}_{2} \mathrm{SO}_{4}(96 \%-97 \%)$ and $0.5 \mathrm{~mL}$ phenol reagent. The mixtures were then left at room temperature for 5 - 10 min before read the absorbance at $490 \mathrm{~nm}$. D-glucose was used as a standard.

\subsubsection{Total Glucan, $\alpha$-Glucan and $\beta$-Glucan Content}

The contents of total glucan and $\alpha$-glucans were determined in the polysaccharide extracts using the Mushroom and Yeast $\beta$-glucan Assay Procedure (Megazyme Int.). The enzyme kit, contains exo 1,3- $\beta$-glucanase, $\beta$-glucosidase, amiloglucosidase, invertase, glucose determination reagent (GOPOD-glucose oxidase, peroxidase, 4-aminoantipyrine) and glucose standard solution. Briefly, the total glucan content polysaccharide samples were hydrolyzed with ice-cold $60 \%$ sulfuric acid (v/v) for $1 \mathrm{~h}$ and for $2 \mathrm{~h}$ at $100^{\circ} \mathrm{C}$. After neutralization, hydrolysis to glucose was carried out using a mixture of exo- $\beta$-(1 $\rightarrow 3)$-D-glucanase plus $\beta$-glucosidase in sodium acetate buffer at $\mathrm{pH} 4.5$ for $1 \mathrm{~h}$ at $40^{\circ} \mathrm{C}$. Total glucan content was measured after GOPOD reagentwas added and absorbance of all solutions was analyzed spectrophotometrically at $510 \mathrm{~nm}$. $\alpha$-glucan contents were measured upon enzymatic hydrolysis with amyloglucosidase plus invertase. The $\beta$-glucan content was calculated by substracting the $\alpha$-glucan from the total glucan content. All values of glucan contents were expressedas $\mathrm{g} / 100 \mathrm{~g}$ of a dry weight (DW) of the extracts.

\section{Results and Discussion}

\subsection{DPPH radical Scavenging}

DPPH is a form of a stable free radical in aqueous or methanol solutions. In chemical reaction, DPPH will accept an electron or hydrogen radical to become a stable diamagnetic molecule. DPPH is usually used as a substrate to evaluate the activity of antioxidants. The reaction was examined by the capacity to decrease the absorbance at $517 \mathrm{~nm}$ of DPPH solution. The free radical DPPH may gain an electron of hydrogen radical to get stable [26] and when antioxidants from the crude extracts donate protons to these radical, the absorption is taken as a measure of the extent of radical scavenging.

Crude extracts from mycelia (EPS EE, IPS CWE, IPS HWE and IPS EE) and from culture filtrate (EPS WE) showed similar pattern of scavenging effect with synthetic antioxidants such as BHA, BHT and ascorbic acid. The percentage of scavenging effect increase as the concentration of crude extract increased. Out of five different types of crude extracts, only EPS EE and EPS WE showed scavenging percentage more than $50 \%$. All the 
crude extracts revealed scavenging activity in the order of EPS EE $>$ EPS WE $>$ IPS CWE $>$ IPS HWE $>$ IPS EE as shown in Figure 1. EPS EE showed the highest radical scavenging effects ( $86 \%$ at $20 \mathrm{mg} / \mathrm{mL}$ ) followed by EPS WE with $60.9 \%$ of scavenging at $20 \mathrm{mg} / \mathrm{mL}$. All crude extracts from mycelium however, revealed low radical scavenging effects. The lowest radical-scavenging effects are from IPS EE which only achieved $20 \%$ of scavenging.

The lowest $\mathrm{IC}_{50}$ value was found in EPS WE with the effective concentration of $0.87 \mathrm{mg} / \mathrm{mL}$ as shown in Figure 2. It was reported that several commercial mushroom revealed scavenging effects on DPPH were moderate to high percentage which were within $42.9 \%-81.8 \%$ at $6.4 \mathrm{mg} / \mathrm{mL}$ [27]. The free radical scavenging activity of Lepistanuda (Bull) Cooke ethanol extracts showed the highest scavenging percentage with the $\mathrm{IC}_{50} 212$ $\mu \mathrm{g} / \mathrm{mL}$ [28]. Choi et al., [29] had also reported that Fomitopsis pinicola mushroom demonstrated the increased of DPPH scavenging rate from $50.3 \%$ to $88.2 \%$ when the F. pinicola extract concentration was increased from 60 to $120 \mu \mathrm{g} / \mathrm{mL}$. The lowest scavenging effects of intracellular polysaccharide (IPS HWE, IPS EE and IPS $\mathrm{CWE}$ ) indicated that these extracts were not effective in scavenging DPPH radicals.

\section{2. $\beta$-Carotene Linoleic Acid Assay}

In this assay, antioxidant capacity was determined by measuring the inhibition of the conjugate dienehydroperoxides arising from linoleic acid oxidation [21]. Antioxidant compounds presence in the crude extracts will enables the neutralization of peroxide compounds, which are linoleic acid oxidation products. Consequently, colour of $\beta$-carotene is preserved. The higher absorbance of the samples showed the higher oxidant activity [21]. A $\beta$-carotene-linoleic acid oxidation was compared with those of Lentinus squarrosulus crude extracts and BHA and BHT.

It was found that inhibition values of EPS EE, IPS EE, EPS WE and IPS HWE increased above $50 \%$ as the concentration of crude extracts increased up to $20 \mathrm{mg} / \mathrm{mL}$. Only IPS CWE did not reach 50\% inhibition (Figure 3). The highest $\beta$-carotene-linoleic acid oxidation obtained from ethanol extract (IPS EE and EPS EE) with IC 50 values of $0.6 \mathrm{mg} / \mathrm{mL}$ and $0.65 \mathrm{mg} / \mathrm{mL}$ respectively. Crude extract of EPS WE showed IC 50 of $1.44 \mathrm{mg} / \mathrm{mL}$ followed by IPS HWE with $\mathrm{IC}_{50}$ value of $5.2 \mathrm{mg} / \mathrm{mL}$ as shown in Figure 4. The studied of sample from L. edodes mushroom methanol extract showed $\beta$-carotene-linoleic acid inhibition $50 \%$ at $3.92 \mathrm{mg} / \mathrm{mL}$ [30].

\subsection{Determination of Phenolic and Flavonoid Compound}

Mushrooms are recognized as one of the important source of biologically active compounds. A variety of secondary metabolites namely phenolic, polyketides, terpenes and steroids are usually accumulated in mushroom and possess a medicinal effects and functional values [31]. Mushrooms that has high phenolic compound are normally well correlated with the antioxidant activity [32]. Table 1 summarizes the total phenolic content obtained from different types of crude extracts of Lentinus squarrosulus. The total phenolic was determined incomparison with standard Gallic acid and the results were expressed in terms of mg Gallic acid/g crude extract. Total phenolic content of these crude extracts were in the range of 0.68 to $0.85 \mathrm{mg} / \mathrm{g}$. EPS WE and IPS EE exhi-

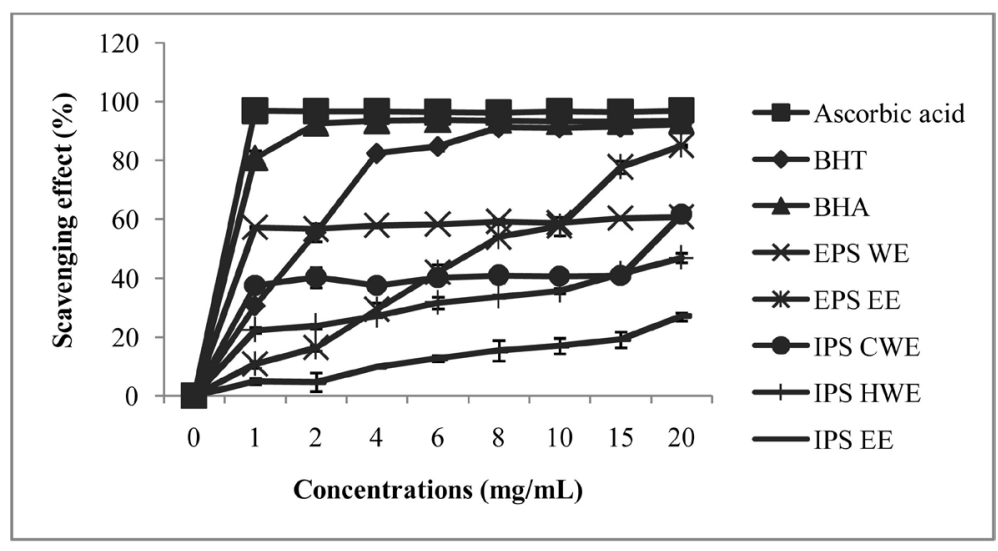

Figure 1. Free radical scavenging effects of the crude extracts measured in DPPH assay. 


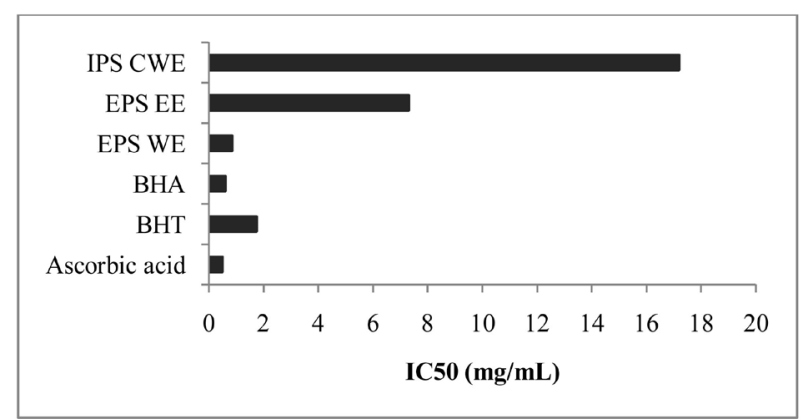

Figure 2. $\mathrm{IC}_{50}$ values of crude extracts measured in $\mathrm{DPPH}$ assay.

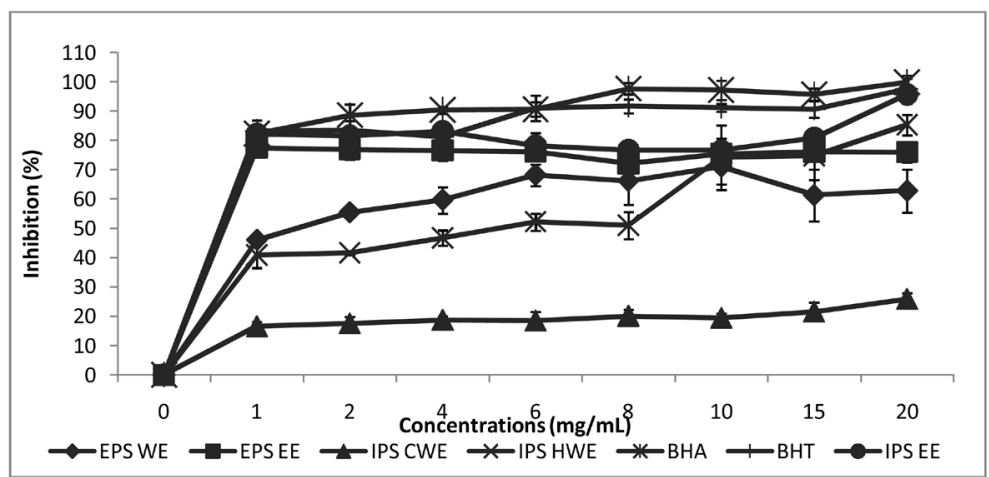

Figure 3. Inhibition of $\beta$-carotene-linoleic acid oxidation of various crude extract.

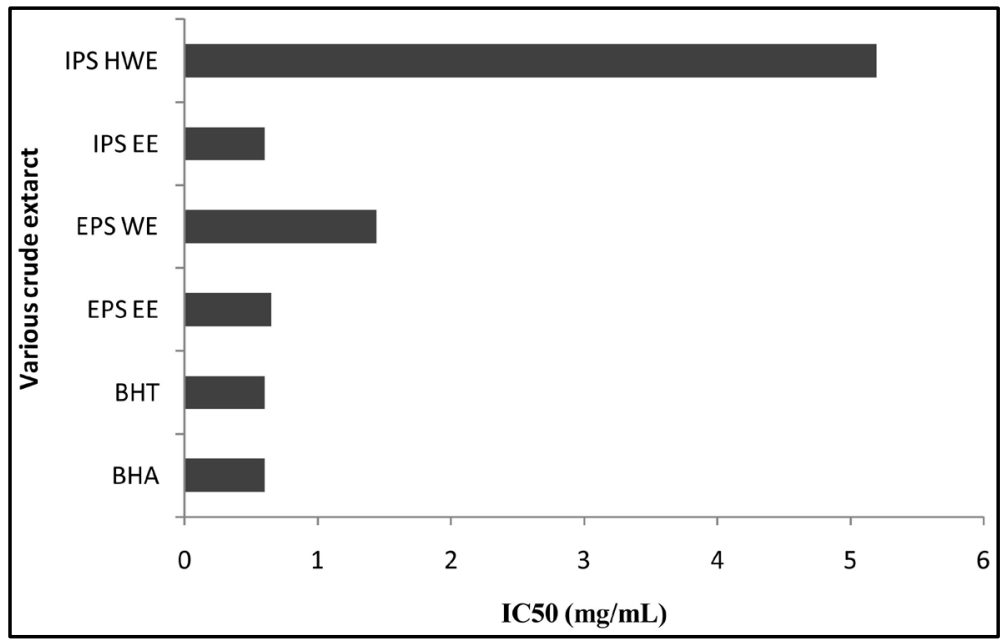

Figure 4. $\mathrm{IC}_{50}$ values of crude extracts measured in $\beta$-carotene-linoleic acid assay.

bited the highest content of phenolic with 0.85 and $0.84 \mathrm{mg} / \mathrm{g}$ respectively. Total phenolic content found in EPS EE $(0.82 \pm 0.01)$ was considerably higher as compared to previous study of ethanolic extract from Lepistanuda mushroom which only showed $0.48 \mathrm{mg} / \mathrm{g}$ [28]. It was suggested that phenolic compound plays an important role in inhibitory effects on mutagenesis [33], stabilizing lipid oxidation and closely associated with antioxidant activity [34]. It is also clearly indicated that EPS EE and EPS WE showing high scavenging percentage of DPPH, and it might be due to the high content of phenolic compound in both of these extracts. Previous research have revealed that the antioxidant activity are associated with the phenol content, probably due to the redox properties 
Table 1. Total phenol and flavonoid compound in various crude extract.

\begin{tabular}{ccc}
\hline Crude & Total Flavanoid Compound & Total Phenolic Compound \\
\hline Extract & $(\mathrm{mg} / \mathrm{g})$ & $(\mathrm{mg} / \mathrm{g})$ \\
EPS WE & $0.58 \pm 0.03$ & $0.85 \pm 0.02$ \\
EPS EE & $0.40 \pm 0.01$ & $0.82 \pm 0.01$ \\
IPS EE & $0.59 \pm 0.01$ & $0.84 \pm 0.03$ \\
IPS HWE & $0.24 \pm 0.03$ & $0.72 \pm 0.03$ \\
IPS CWE & $0.27 \pm 0.01$ & $0.68 \pm 0.01$ \\
\hline
\end{tabular}

which incorporate them as reducing agents, hydrogen donors and singlet oxygen quenchers [35].

Flavanoids are also widely distributed group of plant phenolic compounds which have a very effective antioxidant activity. Total flavonoid content was calculated using quercetin as a standard and the results were expressed as mg of quercetin equivalents per gram of extract. The total flavonoid content of water and ethanolic extracts varied considerable from 0.24 to $0.59 \mathrm{mg} / \mathrm{g}$ as listed in Table 1 . It was showing that IPS EE which highly in total phenol contents also exhibited high total flavonoid content $(0.59 \mathrm{mg} / \mathrm{g})$ as compared to the others crude extract. This followed by EPS WE with $0.58 \mathrm{mg} / \mathrm{g}$ and the lowest flavonoid content was found in IPS CWE with $0.27 \mathrm{mg} / \mathrm{g}$. The most common flavonoids present in mushroom in the group of phenolic acids are quercetin, catechin, epicatechin and rutin [36].

\subsection{Determination of Carbohydrate and Glucan Content}

The content of carbohydrate was determined from various crude extract of Lentinus sq. mushroom mycelia. In general, the content of carbohydrates was mainly high in IPS (IPS CWE, IPS HWE and IPS EE) as compared with EPS (EPS EE, EPS WE). Results exhibited that IPS HWE showed the highest carbohydrate content (19.1 $\mathrm{mg} / \mathrm{mL}$ ) followed by IPS CWE with $16.3 \mathrm{mg} / \mathrm{mL}$ (Figure 5). These results suggested that carbohydrate was found most in mycelium rather than in culture broth.

Experiment was further carried out to determine the total glucan, $\alpha$-glucan and $\beta$-glucan from the several of crude extracts. Mushroom polysaccharides are present mostly as glucans and in general they are polysaccharides containing units of glucose in their backbone. Glucans consists with different types of glycosidic linkages, such as $(1 \rightarrow 3)$, $(1 \rightarrow 6)$ - $\beta$-glucans and $(1 \rightarrow 3)$ - $\alpha$-glucans, but some are heteroglycans. There are also glucans that bind to protein residues and called as PSP complexes. $\beta$-glucan with $\beta$ - $(1 \rightarrow 3)$ linkages in the main chain of the glucan and additional $\beta$ - $(1 \rightarrow 6)$ branch points are most needed for tumor preventive agent [14]. In this sudy, glucans content particularly $\alpha$-glucan and $\beta$-glucans were determined in various water crude extract and ethanolic extract using Mushroom and Yeast $\beta$-glucan Assay Procedure Kit (Megazyme Int.). Total glucans obtained was in the range of 2.2 to 13.1 (\%w/100mg sample) as shown in Figure 6. The highest glucans content was from intracellular water soluble extracts which are IPS HWE with $13.1 \pm 0.3(\% \mathrm{w} / \mathrm{w})$ and $12.3 \pm 0.3$ (\%w/w) respectively. The extracellular polysaccharide EPS EE showed 10.4 \pm 0.4 (\%w/w) and EPS WE with $8.6 \pm 0.1$ (\% w/w). These results indicated culture broth of submerged culture of Lentinus squarrosulus mycelium produced significant glucans content as compared to the mycelium extracts. $\beta$-glucan content was comparatively higher as compared to $\alpha$-glucan content. As contras to total glucan content, $\beta$-glucan content was found highest in IPS CWE with $12.16 \pm 0.68(\% \mathrm{w} / \mathrm{w})$ followed by IPS HWE with $11.36 \pm 0.27(\% \mathrm{w} / \mathrm{w})$. Crude extract of IPS EE showed lowest total glucan as well as $\beta$-glucans with $2.2 \pm 0.4$ and $1.33 \pm 0.38(\% \mathrm{w} / \mathrm{w})$ respectively. The highest total glucans and $\beta$-glucans content form mycelium extracts is in accordance to the previous research which suggested that the main source of antitumor polysaccharides appears to be fungal cell walls that consist of polysaccharides [37]. Results obtained also indicated that crude water extracts from mycelium was potentially become antitumor bioactive compound regarding on the high $\beta$-glucan content.

\section{Conclusion}

In conclusion, the results of this study indicated that the extracellular crude extract (EPS) from culture broth has significant antioxidant activity in DPPH and $\beta$-carotene system. Nevertheless, $\beta$-glucan content was high in intracellular polysaccharide (IPS) from mycelium extract. Therefore EPS could be used as antioxidative agents while the IPS for tumor preventive agents in food industry and cancer treatment respectively. 


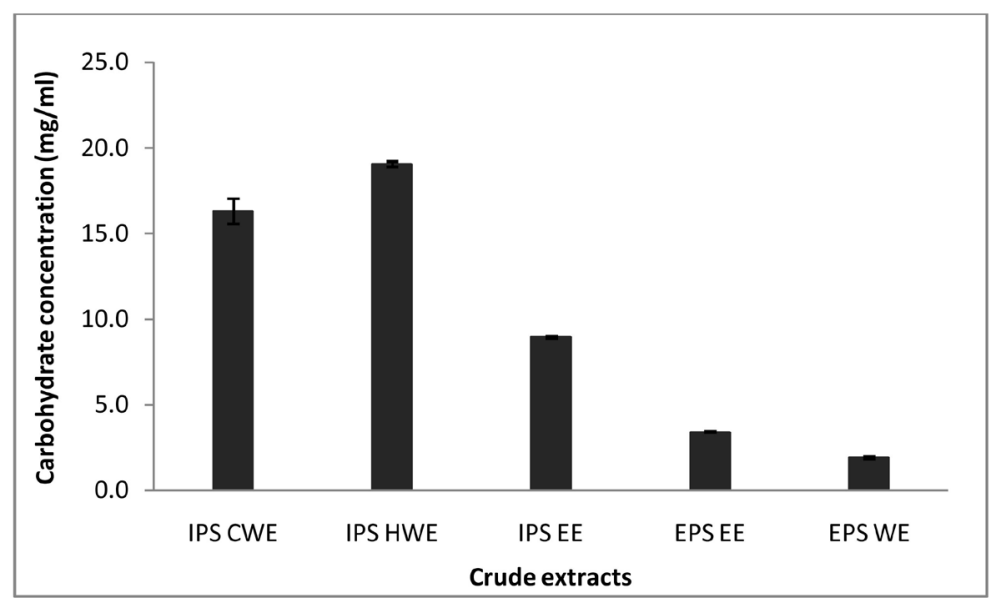

Figure 5. Carbohydrate content from various crude extract.

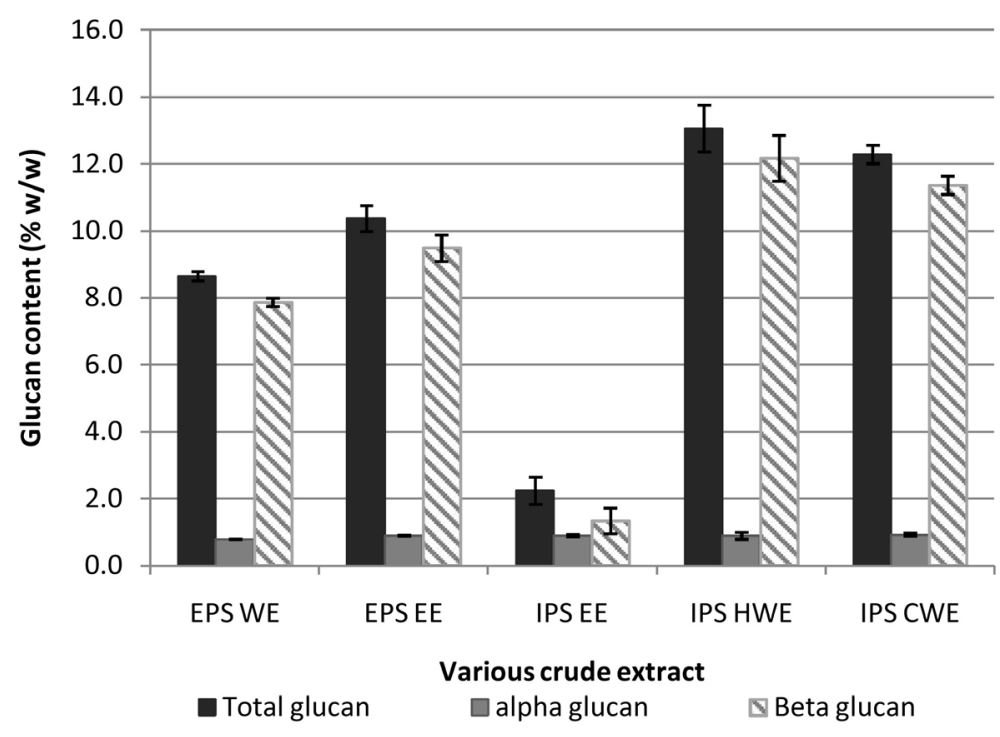

Figure 6. Total glucan, $\alpha$-glucan and $\beta$-glucan content from various crude extract of Lentinus squarrosulus mushroom mycelium.

\section{Acknowledgements}

This work was performed with financial support from eScience fund grant (MOSTI), Project No: 02-01-02SF0978.

\section{References}

[1] Royce, D.J., Bahler, B.D. and Bahler, C.C. (1990) Enhanced Yield of Shiitake by Saccharide Amendment of the Synthetic Substrate. Applied and Environmental Microbiology, 56, 479-482.

[2] Rahayu, A., Al-Shorgani, N.K.N., Hamid, A.A., Yusoff, W.M.W. and Daud, F. (2013) Optimization of Medium Components Using Response Surface Methodology (RSM) for Mycelium Biomass and Exopolysaccharide Production by Lentinus squarrosulus. Advances in Bioscience and Biotechnology, 4, 1079-1085. http://dx.doi.org/10.4236/abb.2013.412144

[3] Ohno, N., Adachi, Y., Suzuki, I., Sato, K., Oikawa, S. and Yadomae, T. (1986) Characterization of the Antitumor Glucan Obtained from Liquid-Cultured Grifolafrondosa. Chemical and Pharmaceutical Bulletin, 34, 1709-1715. http://dx.doi.org/10.1248/cpb.34.1709

[4] Wang, H. and Tang, T.B. (2000) Isolation of a Novel Ubiquitin-Like Protein from Pleurotus ostreatus Mushroom with 
Anti-Human Immunodeficiency Virus, Translation-Inhibitory and Ribonuclease Activities. Biochemical and Biophysical Research Communications, 275, 810-816. http://dx.doi.org/10.1006/bbrc.2000.3373

[5] Opletal, L., Jahodar, L., Chobot, V., Zdansky, P., Lukes, J., Bratova, M., Solichova, D., Blunden, G., Dacke, C.G. and Patel, A.V. (1997) Evidence for the Anti-Hyperlipidaemic Activity of the Edible Fungus Pleurotus ostreatus. British Journal of Biomedical Science, 54, 240-243.

[6] Cha, W.S., Choi, D.B. and Kang, S.H. (2004) Optimization of Culture Media for Solid-State Culture of Pleurotus ferulae. Biotechnology and Bioprocess Engineering, 9, 369-373. http://dx.doi.org/10.1007/BF02933059

[7] Choi, D.B., Cha, W.S., Kang, S.H. and Lee, B.R. (2004) Effect of Pleurotus ferulae Extracts on Viability of Human Lung Cancer and Cervical Cancer Cell Lines. Biotechnology and Bioprocess Engineering, 9, 356-361. http://dx.doi.org/10.1007/BF02933057

[8] Huang, D., Ou, B. and Prior, R.L. (2005) The Chemistry behind Antioxidant Capacity Assays. Journal of Agricultural and Food Chemistry, 53, 1841-1856. http://dx.doi.org/10.1021/jf030723c

[9] Halliwell, B. and Gutteridge, J.M.C. (1984) Lipid Peroxidation, Oxygen Radicals, Cell Damage, and Antioxidant Therapy. The Lancet, 323, 1396-1397. http://dx.doi.org/10.1016/S0140-6736(84)91886-5

[10] Yang, J.H., Lin, H.C. and Mau. J.L. (2002) Antioxidant Properties of Several Commercial Mushrooms. Food Chemistry, 77, 229-235. http://dx.doi.org/10.1016/S0308-8146(01)00342-9

[11] Kang, K.A., Chae, S., Lee, K.H., Zhang, R., Jung, M.S., You, H.J., Kim, J.S. and Hyun, J.W. (2005) Antioxidant Effect of Homogentisic Acid on Hydrogen Peroxide Induced Oxidative Stress in Human Lung Fibroblast Cells. Biotechnology and Bioprocess Engineering, 10, 556-563. http://dx.doi.org/10.1007/BF02932294

[12] Asfors, K.E. and Ley, K. (1993) Sulfated Polysaccharides in Inflammation. Journal of Laboratory and Clinical Medicine, 121, 201-202.

[13] Longvah, T. and Deosthale, Y.G. (1998) Compositional and Nutritional Studies on Edible Wild Mushroom from Northeast India. Food Chemistry, 63, 331-334. http://dx.doi.org/10.1016/S0308-8146(98)00026-0

[14] Wasser, S.P. (2002) Medicinal Mushrooms as a Source of Antitumor and Immunomodulating Polysaccharides. Applied Microbiology and Biotechnology, 60, 258-274. http://dx.doi.org/10.1007/s00253-002-1076-7

[15] Omar, N.A.M., Abdullah, A., Kuppusamy, U.R., Abdullah, M.A. and Sabaratnam, V. (2011) Nutritional Composition, Antioxidant Activities and Antiulcer Potential of Lentinus squarrosulus (Mont.) Mycelia Extract. Evidence-Based Complementary and Alternative Medicine, 2011, Article ID: 539356. http://dx.doi.org/10.1155/2011/539356

[16] Bae, J.T., Sinha, J., Park, J.P., Song, C.H. and Yun, J.W. (2000) Optimization of Submerged Culture Conditions for Exobiopolymer Production by Paecilomyces japonica. Journal of Microbiology and Biotechnology, 10, 482-487.

[17] Zhang, H., Wang, Z.Y., Yang, L., Yang, X., Wang, X. and Zhang, Z. (2011) In Vitro Antioxidant Activities of Sulfated Derivatives of Polysaccharides Extracted from Auricularia auricular. International Journal of Molecular Sciences, 12, 3288-3302. http://dx.doi.org/10.3390/ijms12053288

[18] Cuendet, M., Hostettmann, K., Potterat, O. and Dyatmiko, W. (1997) Irdiod Glucosidase with Free Radical Scavenging Properties from Fagraea blumei. Helvetica Chimica Acta, 80, 1144-1152. http://dx.doi.org/10.1002/hlca.19970800411

[19] Burits, M. and Bucar, F. (2000) Antioxidant Activity of Nigella sativa Essential Oil. Phytotherapy Research, 14, 323328.

[20] Reis, F.S., Ferreira, I.C.F.R., Barros, L. and Martins, A. (2011) A Comparative Study of Tocopherols Composition and Antioxidant Properties of in Vivo and in Vitro Ectomycorrhizal Fungi. Food Science and Technology, 44, 820-824.

[21] Dapkevicius, A., Venskutonis, R., Van Beek, T.A. and Linssen, P.H. (1998) Antioxidant Activity of Extracts Obtained by Different Isolation Procedures from Some Aromatic Herbs Grown in Lithuania. Journal of the Science of Food and Agriculture, 77, 140-146.

[22] Slinkard, K. and Singleton, V.L. (1977) Total Phenol Analyses: Automation and Comparison with Manual Methods. American Journal of Enology and Viticulture, 28, 49-55.

[23] Heleno, S.A, Barros, L., Sousa, M.J., Martins, A. and Ferreira, I.C.F.R. (2010) Tocopherols Composition of Portoguese Wild Mushrooms with Antioxidant Capacity. Food Chemistry, 119, 1443-1450. http://dx.doi.org/10.1016/j.foodchem.2009.09.025

[24] Park, Y.K., Koo, M.H., Ikegaki, M. and Contado, J.L. (1997) Comparison of the Flavonoid Aglycone Contents of Apis mellifera Propolis from Various Regions of Brazil. Arquivos de Biologiae Technologia, 40, 97-106.

[25] Fournier, E. (2001) Colorimetric Quatification of Carbohydrates. In: Ronald, E.W., Terry, E.A., Eric, A.D., Michael, H.P., David, S.R., Steven, J.S., Charles, F.S., Denise, M.S. and Peter, S., Eds., Current Protocols in Food Analytical Chemistry, John Wiley \& Sons, Inc., Hoboken, E1.1.1-E1.1.8.

[26] Soares, J.R., Dins, T.C.P., Cunha, A.P. and Almeida, L.M. (1997) Antioxidant Activity of Some Extracts of Thymus zygis. Free Radical Research, 26, 469-478. http://dx.doi.org/10.3109/10715769709084484 
[27] Yang, J.H., Lin, H.C. and Mau, J.L. (2001) Non-Volatile Taste Components of Several Commercial Mushrooms. Food Chemistry, 72, 465-471. http://dx.doi.org/10.1016/S0308-8146(00)00262-4

[28] Mercan, N., Duru, M.E., Turkoglu, A., Gezer, K., Kivrak, I. and Turkoglu, H. (2006) Antioxidant and Antimicrobial Properties of Ethanolic Extract from Lepista nuda (Bull.) Cooke. Annals of Microbiology, 56, 339-344.

[29] Choi, D.B., Park, S.S., Ding, J.L. and Cha, W.S. (2007) Effects of Fomitopsis pinicola Extracts on Antioxidant and Antitumor Activities. Biotechnology and Bioprocess Engineering, 12, 516-524. http://dx.doi.org/10.1007/BF02931349

[30] Reis, F.S., Martins, A., Barros, L. and Ferreira, I.C.F.R. (2012) Antioxidant Properties and Phenolic Profile of the Most Widely Appreciated Cultivated Mushrooms: A Comparative Study between in Vivo and in Vitro Samples. Food and Chemical Toxicology, 50, 1201-1207. http://dx.doi.org/10.1016/j.fct.2012.02.013

[31] Turkoglu, A., Duru, M.E., Mercan, N., Kivrak, I. and Gezer, K. (2007) Antioxidant and Antimicrobial Activities of Laetiporus sulphureus (Bull.) Murill. Food Chemistry, 101, 267-273. http://dx.doi.org/10.1016/j.foodchem.2006.01.025

[32] Cheung, L.M., Cheung, C.K. and Ooi, V.E.C. (2003) Antioxidant Activity and Total Phenolics of Edible Mushroom Extracts. Food Chemistry, 81, 249-255. http://dx.doi.org/10.1016/S0308-8146(02)00419-3

[33] Tanaka, M., Kuei, C.W., Nagashima, Y. and Taguchi, T. (1998) Application of Antioxidative Maillrad Reaction Products from Histidine and Glucose to Sardine Products. Nippon Suisan Gakkaishil, 54, 1409-1414.

[34] Yen, G.C., Duh, P.D. and Tsai, C.L. (1993) Relationship between Antioxidant Activity and Maturity of Peanut Hulls. Journal of Agricultural and Food Chemistry, 41, 67-70. http://dx.doi.org/10.1021/jf00025a015

[35] Chang, S.T., Wu, J.H., Wang, S.Y., Kang, P.L., Yang, N.S. and Shyur, L.F. (2001) Antioxidant Activity of Extracts from Acacia Confuse Bark and Heartwood. Journal of Agricultural and Food Chemistry, 49, 3420-3424. http://dx.doi.org/10.1021/jf0100907

[36] Kolayli, S., Sahin, H., Aliyazicioglu, R. and Sesli, E. (2012) Phenolic Components and Antioxidant Activity of Three Edible Wild Mushrooms from Trabzon, Turkey. Chemistry of Natural Compounds, 48, 137-140. http://dx.doi.org/10.1007/s10600-012-0182-8

[37] Mizuno, T., Saito, H., Nishitoba, T. and Kawagashi, H. (1995) Antitumor-Active Substances from Mushrooms. Food Reviews International, 11, 23-61. http://dx.doi.org/10.1080/87559129509541018 
Scientific Research Publishing (SCIRP) is one of the largest Open Access journal publishers. It is currently publishing more than 200 open access, online, peer-reviewed journals covering a wide range of academic disciplines. SCIRP serves the worldwide academic communities and contributes to the progress and application of science with its publication.

Other selected journals from SCIRP are listed as below. Submit your manuscript to us via either submit@scirp.org or Online Submission Portal.
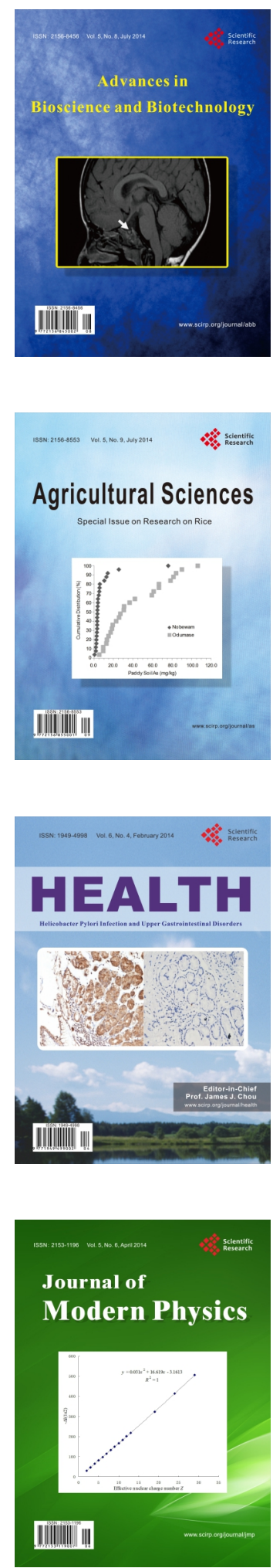
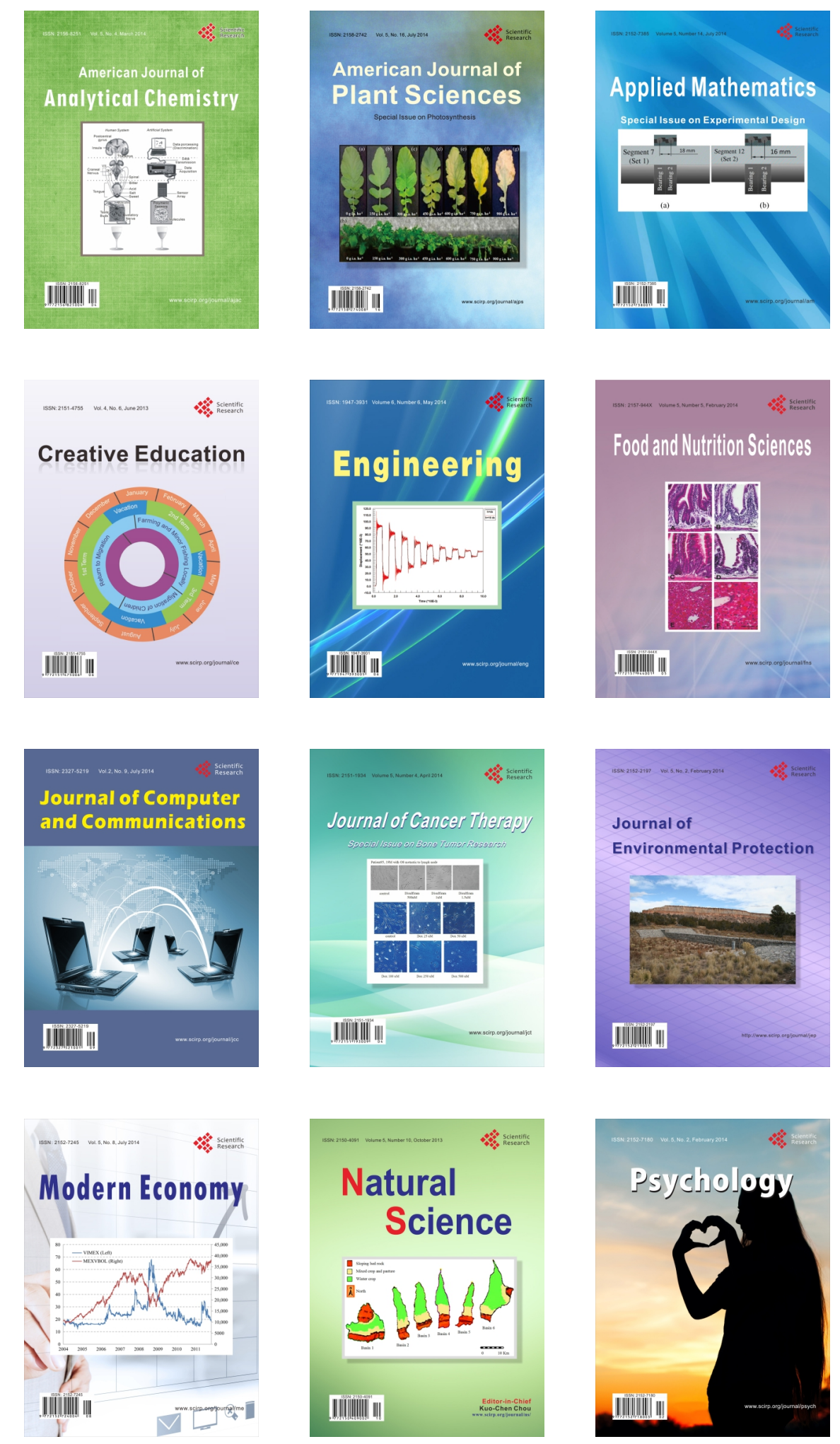